\title{
Comparative Study on CFRP and GFRP Composite in Strengthening of RC Slab
}

\author{
Balamurugan G. ${ }^{1}$ Viswanathan T.S 2* $^{*}$ \\ ${ }^{1}$ Research Scholar, Department of Structural and Geotechnical Engineering, School of Civil Engineering, Vellore Institute of \\ Technology, Vellore, Tamil Nadu, India, 632014 \\ ${ }^{2}$ Associate Professor, Department of Structural and Geotechnical Engineering, School of Civil Engineering, Vellore Institute of \\ Technology, Vellore, Tamil Nadu, India, 632014 \\ ${ }^{1}$ Assistant Professor, Department of Civil Engineering, Madanapalle Institute of Technology and Science, Madanapale, Andhra \\ Pradesh, India, 517325 \\ *Corresponding author : viswanathan.ts@ vit.ac.in
}

\begin{abstract}
In order to strengthen the concrete structures, the use of Fiber Reinforced Polymer (FRP) composites has increased recently. Rather, numerous factors inducing the strength of the FRPs composites are unknown. The experimental investigation carried out to study the effect of Carbon Fiber Reinforced Polymer (CFRP) and Glass Fiber Reinforced Polymer (GFRP) composites by different orientation and coverage area on flexural strength and crack propagation of the Reinforced Concrete (RC) slabs. Five different patterns followed to access the effective orientation and coverage area of the CFRP and GFRP composites. The comparison of the results shows that in the strengthening of the slab, GFRP is more effective. In all the patterns, CFRP/GFRP sheets effectively minimize the crack width..
\end{abstract}

Key words: RC Slab, CFRP, GFRP, Crack Pattern, Crack Width and Flexural strength

\section{INTRODUCTION}

Use of superficially bonded Fiber Reinforced Polymers (FRPs) composites have lately established significant attention amongst the rehabilitation community. It is due to high strength induced in the load-bearing component. In the past, the researchers have conveyed an escalation in the structural capacity of slabs due to the FRP strengthening and it schemes [2, 5, 6, 8, and 16]. In addition to this, FRPs have a high ratio of strength and stiffness to density and are resistant to corrosion [4, 9 and 17].

The ultimate capacity of unreinforced and reinforced concrete slabs repaired and retrofitted with FRP composite strips evaluated by Mosalla et al. [15]. The test results showed that Carbon Fiber Reinforced Polymer (CFRP) and Glass Fiber Reinforced Polymer (GFRP) with epoxy were effective as a system. It is significantly increased the strength of repaired slabs to around five times than control slabs. In the case of CFRP composite, it is significantly effective in reducing the deflection and increasing the ultimate loadcarrying capacity [1-3 and 7].
A certain application of slabs like the use of maintenance hole cover or as a cover for a well of small diameter does necessitate the requirement of a thicker slab compared to its planar dimension. The present research aims to study the effect of orientation and coverage area in flexural strength and crack propagation of the thicker RC slabs strengthened with CFRP and GFRP composites. For this, five different Patterns were followed to compare the effectiveness.

\section{EXPERIMENTAL PROGRAM}

To test the flexural strengths and deflections, 33 slabs were cast using a dimension of $350 \mathrm{~mm} \times 350 \mathrm{~mm} \times 75 \mathrm{~mm}$. A clear cover of $20 \mathrm{~mm}$ and reinforced with an $8 \mathrm{~mm}$ diameter rebar at $150 \mathrm{~mm}$ center to center spacing was followed. For comparative study of CFRP and GFRP composite in strengthening of RC slab, five strengthening patterns $A, B, C$, $D$, and $E$ were used. The patters chosen to study the effect of FRP composites in strengthening of RC slab with different orientation and coverage area. Three specimens were considered for each strengthening patterns with CFRP and GFRP sheets as well as the control specimens.

The FRP strips were cut into $160 \mathrm{~mm} \times 160 \mathrm{~mm}$ for patterns $\mathrm{A}, \mathrm{B}$, and D while pattern C, $320 \mathrm{~mm} \times 160 \mathrm{~mm}$ used. For pattern E, the FRP strips sized $320 \mathrm{~mm} \times 320 \mathrm{~mm}$. It wrapped as a single layer on the tension face of slabs. The orientation of the FRPs in strengthening patterns $\mathrm{A}, \mathrm{B}, \mathrm{C}, \mathrm{D}$, and $\mathrm{F}$ are Edge, Corner, Half, Center, and Full respectively was used.

\section{MATERIAL PROPERTIES}

Stream sand used as fine aggregate and remained sieved through $4.75 \mathrm{~mm}$ sieve size to discard the aggregate particle diameter higher than $4.75 \mathrm{~mm}$ to conform IS 383: 1970 [11]. The cement used for the experiment was Ordinary-PortlandCement (OPC) Premium 53-Grade, in compliance to IS 269: 2015 [10]. Crusted gravels passing through $19 \mathrm{~mm}$ and retained on $20 \mathrm{~mm}$ sieve,meeting the requirements to IS 383 : 1970 used as coarse aggregate [11]. Portable water used for the preparation of concrete mix. High-Yielding-Strength- 
Balamurugan G. et al., International Journal of Emerging Trends in Engineering Research, 8(9), September 2020, 5424 - 5429

Deformed (Fe415) steel-bars with $8 \mathrm{~mm}$ diameter was used as reinforcement of slabs [14]. The material store in a dry place to maintain quality without changes

\subsection{Fiber Reinforced Polymer}

For strengthening of RC slab specimens, CFRP and GFRP sheets used. The properties of FRPs be presented in Table 1

Table 1:Properties of Fiber Reinforced Polymer.

\begin{tabular}{|c|c|c|c|}
\hline Parameter & CFRP & GFRP & Unit \\
\hline Fiber type & $\begin{array}{c}\text { High strength } \\
\text { carbon fiber }\end{array}$ & $\begin{array}{c}\text { High strength } \\
\text { glass fiber }\end{array}$ & - \\
\hline $\begin{array}{c}\text { Fiber } \\
\text { orientation }\end{array}$ & Unidirectional & Unidirectional & - \\
\hline Weight of fiber & 200 & 920 & $\mathrm{~g} / \mathrm{m}^{2}$ \\
\hline Density of fiber & 1.80 & 2.6 & $\mathrm{~g} / \mathrm{cc}$ \\
\hline Fiber thickness & 0.30 & 0.90 & $\mathrm{~mm}$ \\
\hline Tensile strength & 3500 & 3400 & $\mathrm{~N} / \mathrm{mm}^{2}$ \\
\hline $\begin{array}{c}\text { Tensile } \\
\text { Modulus }\end{array}$ & 285000 & 73000 & $\mathrm{~N} / \mathrm{mm}^{2}$ \\
\hline
\end{tabular}

\subsection{Bonding Material}

Primer and Saturant were used as bonding agent (epoxy). Both primer and saturant are consists of base and hardner. The properties of the bonding materials are presented in Tables 2

Table 2:Properties of bonding agent (epoxy).

\begin{tabular}{|c|c|c|}
\hline Parameter & Primer & Saturant \\
\hline Density & $1.14 \mathrm{~g} / \mathrm{cc}$ & $1.25-1.26 \mathrm{~g} / \mathrm{cc}$ \\
\hline Pot life & 25 min. @ $27^{\circ} \mathrm{C}$ & 2 hours @ $30^{\circ} \mathrm{C}$ \\
\hline Full Cure & 7 days & 5 days \\
\hline Application temperature & $25^{\circ} \mathrm{C}-35^{\circ} \mathrm{C}$ & $15^{\circ} \mathrm{C}-40^{\circ} \mathrm{C}$ \\
\hline Colour & Clear & $\begin{array}{c}\text { Pale yellow to } \\
\text { amber }\end{array}$ \\
\hline
\end{tabular}

\section{SPECIMEN PREPARATION AND TESTING}

For casting of slabs, the wooden moulds were used. The reinforcement placed with a $20 \mathrm{~mm}$ cover; subsequently, fresh concrete was placed in mould [12]. In order to confirm the quality of concrete, cubes were cast and tested. It noticed that the average-compressive-strength of the concrete-cube is $26.30 \mathrm{~N} / \mathrm{mm}^{2}$. The slab was un-molded after 24 hours, and the specimens kept in curing tank for 28 days.

All the slabs were tested in 50 tons digital Loading Frame, which has the least count of $0.1 \mathrm{kN}$. Necessary markings are done on the specimens before the test. The slabs supported simply on all four sides [13]. The experiment performed under the point load at the center of the slab specimens with at a rate of $0.5 \mathrm{kN} / \mathrm{sec}$, as shown in Fig. 1.

\section{STRENGTHENING OF SLAB SPECIMENS}

The slabs were taken out from tank after the curing period. Its tension face was smoothed by using the sandpaper to obtain an even surface and to prevent premature de-bonding failure of FRP sheets. Primer and saturant were used as adhesive to wrap the FRP sheets. It was prepared by mixing hardener and base in the ratio of $1: 9$ and 1:1.2. The first coat of primer applied on the slab then after 24 hours saturant applied over the track free primer. Subsequently, the FRPs were wrapped on the tension face of the slab. Measures were taken to ensure that fiber orientation without disturbance during the second coat of saturant (after 30 minutes). The strengthened slabs were kept in atmospheric curing five days before the test.

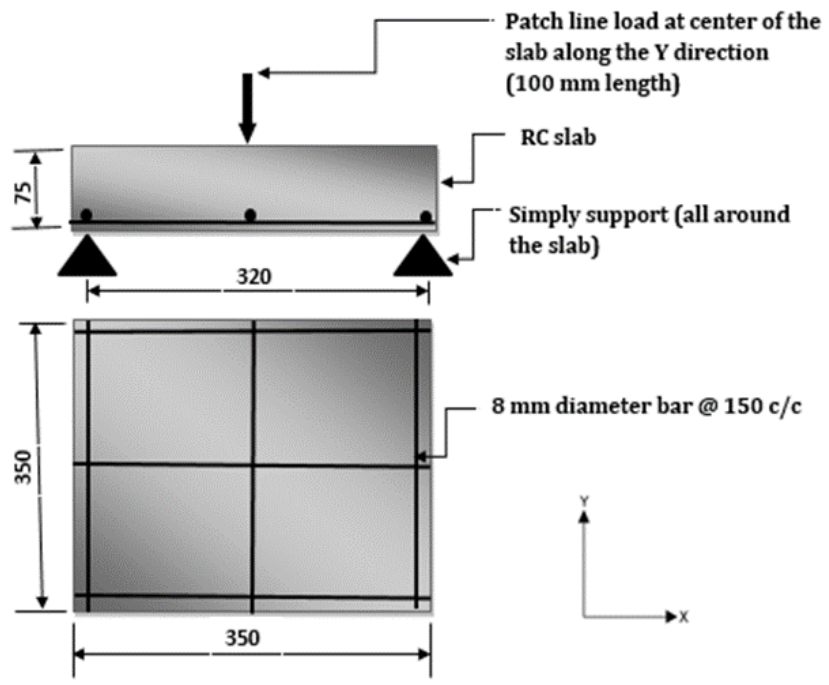

Figure 1: Experimental setup

\section{TEST RESULT AND DISCUSSION}

\subsection{Maximum crack width}

The maximum crack width of strengthened specimens are presented in Table 3. It is observed that, all strengthening patterns have lesser maximum-crack-width than the control slab. It is as a result of fiber reinforced polymer (FRP) sheets on controlling together the crack spread and width. These decreases in the crack widths lead to a notable enhancement in the serviceability of the slabs. Though, the reductions differs observed, it is depending on the strengthening pattern used. The maximum reduction of crack width is noticed in Pattern-C. The comparison shows that the CFRP strips provide the lesser maximum crack width than the GFRP strips in all the strengthening patterns. It is assumed that due to the lesser density, higher tensile strength and tensile modules than GFRP composite. 
Balamurugan G. et al., International Journal of Emerging Trends in Engineering Research, 8(9), September 2020, $5424-5429$

Table 3: The maximum crack width of slabs.

\begin{tabular}{|c|l|l|l|}
\hline \multicolumn{2}{|c|}{ Pattern } & $\begin{array}{l}\text { Maximum } \\
\text { crack width } \\
(\text { mm) }\end{array}$ & $\begin{array}{l}\text { \% reducing in } \\
\text { maximum crack } \\
\text { width concerning the } \\
\text { control slab (mm) }\end{array}$ \\
\hline $\begin{array}{c}\text { Control Slab } \\
(\text { CS })\end{array}$ & - & 1.7 & - \\
\hline \multirow{2}{*}{ Pattern- $A$} & CFRP & 0.9 & 47.06 \\
\cline { 2 - 4 } & GFRP & 1.1 & 35.29 \\
\hline \multirow{2}{*}{ Pattern- $B$} & CFRP & 1 & 41.18 \\
\cline { 2 - 4 } & GFRP & 1.4 & 17.65 \\
\hline \multirow{2}{*}{ Pattern- $C$} & CFRP & 0.2 & 88.24 \\
\cline { 2 - 4 } & GFRP & 0.4 & 76.47 \\
\hline \multirow{2}{*}{ Pattern- $D$} & CFRP & 0.8 & 52.94 \\
\cline { 2 - 4 } & GFRP & 1 & 41.18 \\
\hline & CFRP & 0.7 & 58.82 \\
\hline & GFRP & 1.2 & 29.41 \\
\hline \multirow{2}{*}{ Pattern- $E$} & & & \\
\hline & & & \\
\hline
\end{tabular}

6.2 Cracks pattern
The first-crack and ultimate-loadexperimental results of strengthened slabs in comparison with control slab specimens shown in Table 4.

Control Slab: When the load applied gradually to the slab, the crack forms initialy on the tension face of the slabs below the loaded area. As the load increased, orthogonal-crack appears on tension face. It extends from the center of the slab to edge as shown in Fig. 2.

In Pattern-A, the first crack was observed nearer to the center of the slab in both FRPs. Further, the crack extend along the center line of the slab towards the edge up to the failure load in CFRP slab (Fig. 3(a)). In GFRP slab, crack extends towards the edge of a slab and at ultimate load level delamination occurs. The crack pattern observed as nonorthogonal flexural crack in GFRP slab is as shown in Fig. 3(b). It is assumed that the difference in failure mode is due to the higher density than CFRP sheet and higher deflection in GFRP slab.

In Pattern-B, the crack initialy was observed on the tension face of the slab under load point in both FRPs. The crack propagation was found as a non-orthogonal flexural crack. It is due to regular crack route that blocked and deviated by deployment of FRPs at the corner of the slabs as shown in Fig

Table 4: The result of first crack and ultimate load of strengthened slabs.

\begin{tabular}{|c|c|c|c|c|c|c|}
\hline \multicolumn{2}{|c|}{ Pattern } & $\begin{array}{l}\text { First } \\
\text { crack- } \\
\text { load }(k N)\end{array}$ & $\begin{array}{l}\text { Ultimate } \\
\text {-load } \\
(\mathrm{kN})\end{array}$ & $\begin{array}{l}\text { \% increase in the first } \\
\text { crack loads with respect } \\
\text { to control slab }\end{array}$ & $\begin{array}{l}\% \text { increase in the } \\
\text { ultimate loads with } \\
\text { respect to control slab }\end{array}$ & $\begin{array}{l}\text { Difference in \% increase in the } \\
\text { ultimate loads between CFRP } \\
\text { and GFRP slabs }\end{array}$ \\
\hline $\mathrm{CS}$ & _ & 29.4 & 38.9 & _ & _ & _ \\
\hline \multirow{2}{*}{ Pattern-A } & CFRP & 35.2 & 46.4 & 19.73 & 19.28 & \multirow{2}{*}{18.4} \\
\hline & GFRP & 46 & 55.1 & 56.46 & 41.65 & \\
\hline \multirow{2}{*}{ Pattern-B } & CFRP & 44.4 & 54.8 & 51.02 & 40.87 & \multirow{2}{*}{5.4} \\
\hline & GFRP & 54 & 57.8 & 83.67 & 48.59 & \\
\hline \multirow{2}{*}{ Pattern-C } & CFRP & 56.5 & 69.3 & 92.18 & 78.15 & \multirow{2}{*}{4.3} \\
\hline & GFRP & 57 & 72.3 & 93.88 & 85.86 & \\
\hline \multirow{2}{*}{ Pattern-D } & CFRP & 58 & 70.1 & 97.28 & 80.21 & \multirow{2}{*}{7.5} \\
\hline & GFRP & 62 & 75.4 & 110.88 & 93.83 & \\
\hline \multirow{2}{*}{ Pattern-E } & CFRP & 67.1 & 74.5 & 128.23 & 91.52 & \multirow{2}{*}{9.3} \\
\hline & GFRP & 69.7 & 81.7 & 137.07 & 110.03 & \\
\hline
\end{tabular}

In Pattern-C also the first crack was noticed on the tension face of slab under load point. Further, the crack propagation appeared around the FRP strip, than which extended to corners in CFRP slab (Fig. 5(a)). In GFRP slab, the cracks extended under sheet then de-lamination occurred at the failure load level as shown in Fig. 5(b). It is assumed that the difference is in failure mode due to higher density than CFRP sheet and higher deflection in GFRP slab.

In Pattern-D, the first crack was observed around FRPs. It extends to the corners of slabs in both FRPs, then failure occurred at the end due to de-lamination. The nonorthogonal flexural cracks were observed under FRP sheets as failure mode as shown in Fig. 6.
In Pattern- E, the de-lamination of FRPs strips observed at the ultimate load level. It is due to the full wrapping deployed on slab specimens in this pattern. The crack propagation observed in this pattern under the FRP as nonorthogonal cracks are shown as in Fig. 7.

In CFRP slabs all the pattern delamination was noticed except in Pattern-B. It is due to the orientation of FRP. In Pattern- D and E only with both FRPs, the delamination occurred and it is assumed that due to FRP orientation, which is center and full wrapping deployed on the slabs. 


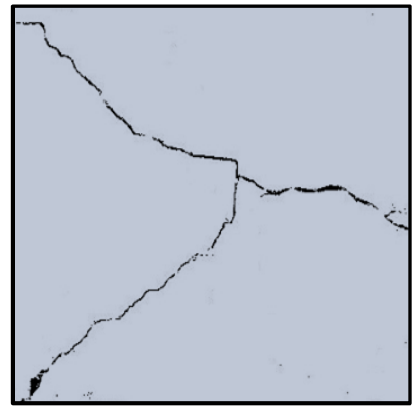

Figure 2: Control specimen crack propagation
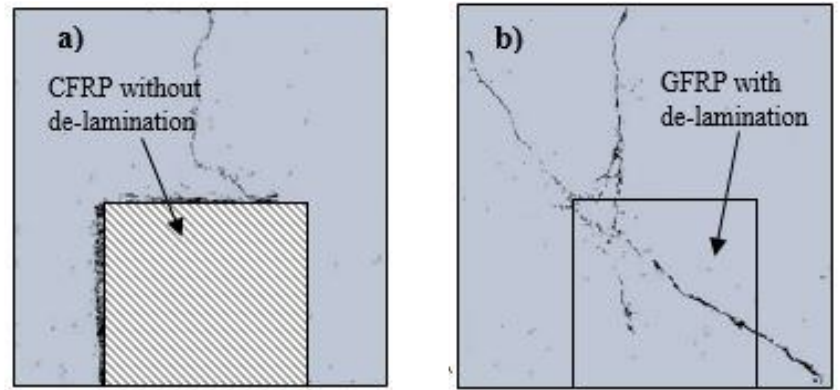

Figure 3: Pattern- $A$ crack propagation: (a) CFRP; (b) GFRP
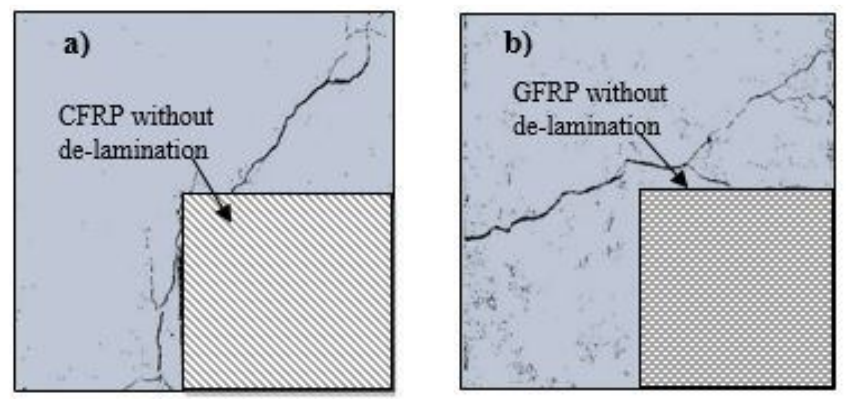

Figure 4: Pattern- $B$ crack propagation: (a) CFRP; (b) GFRP
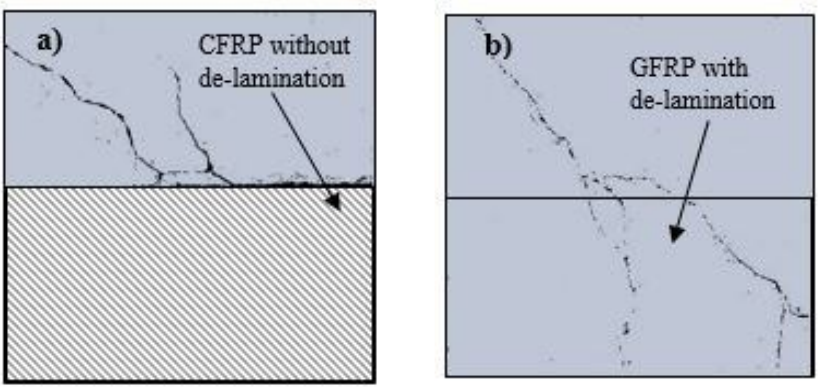

Figure 5: Pattern- $C$ crack propagation: (a) CFRP; (b) GFRP
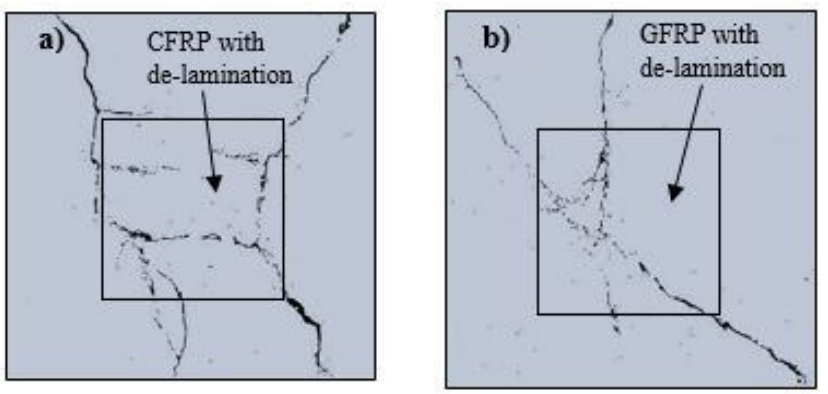

Figure 6: Pattern- $D$ crack propagation: (a) CFRP; (b) GFRP
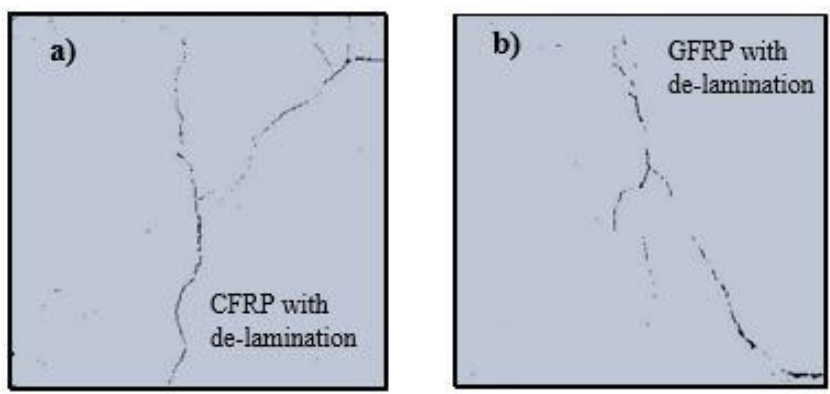

Figure7: Pattern- $E$ crack propagation: (a) CFRP; (b) GFRP

\subsection{Load-deflection behavior}

The load-deflection response of CFRP and GFRP strengthened the slabs in comparison with the control slab specimens shown in Fig. 8 and 9.

In Pattern-A, the deflection of CFRP slab was two times lesser than GFRP slab. It is also noticed that deflection of CFRP slab exhibits about 39\% lesser than the control specimen, whereas the GFRP slab is $73 \%$ higher.

In Pattern-B, the comparison of both FRPs shows the loaddeflection behavioral differences. It is assumed that due to the differences in the density ratio of the GFRP and CFRP sheet might contribute to the differences in the behavior of load-deflection. The flexural strength of the slab in this pattern is much higher than the control slab. In the case of deflection of GFRP slab, it is almost equal to the control specimen deflection. Whereas, the GFRP slab exhibits 2times higher deflection at the ultimate load level.

In Pattern-C, the deflection of the CFRP slab reduced almost by $50 \%$ when compared with control specimen. It is $25 \%$ lesser when compared with GFRP strengthened slab. When considering this load carrying capacity, it's effectively increases the flexural strength of slab than Pattern- A and B with both FRPs.

The case of Pattern-D with both FRPs, considerably reduces the deflection with higher load carrying capacity. In this pattern, the load carrying capacity is higher than Pattern- A, $\mathrm{B}$ and C. The deflection in Pattern-E was $28 \%$ and $42 \%$ higher than control specimen in CFRP and GFRP slabs respectively. It provides the higher load carrying capacity than any other patterns.

Using FRP sheets gives on to notable upgrading in load carrying ability of RC-slabs. It depends on the FRP sheets strengthening pattern used and the load carrying abilityimproved by about $19-91 \%$ in CFRP slabs. While slabs strengthened with GFRP sheet increased by about 41$110 \%$. 


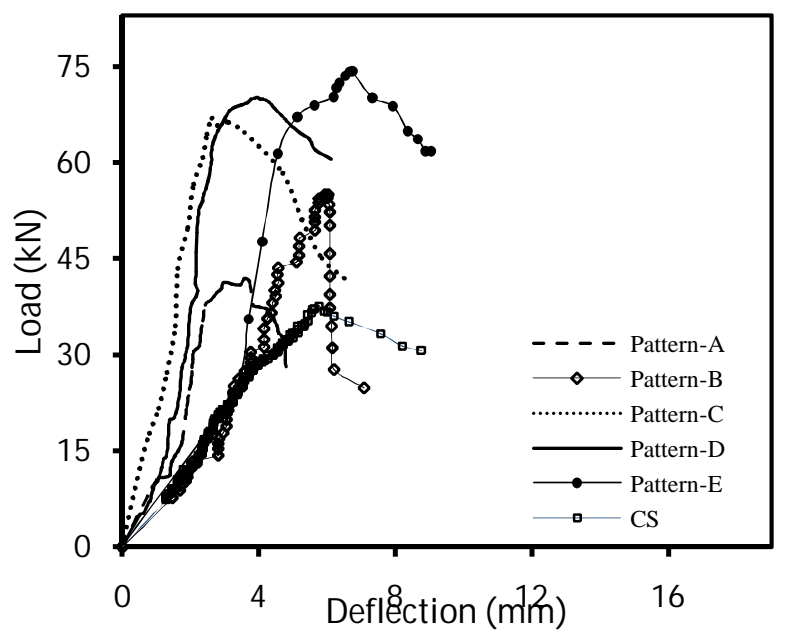

Figure 8: Load- deflection Curve of CFRP slabs with control slab (CS)

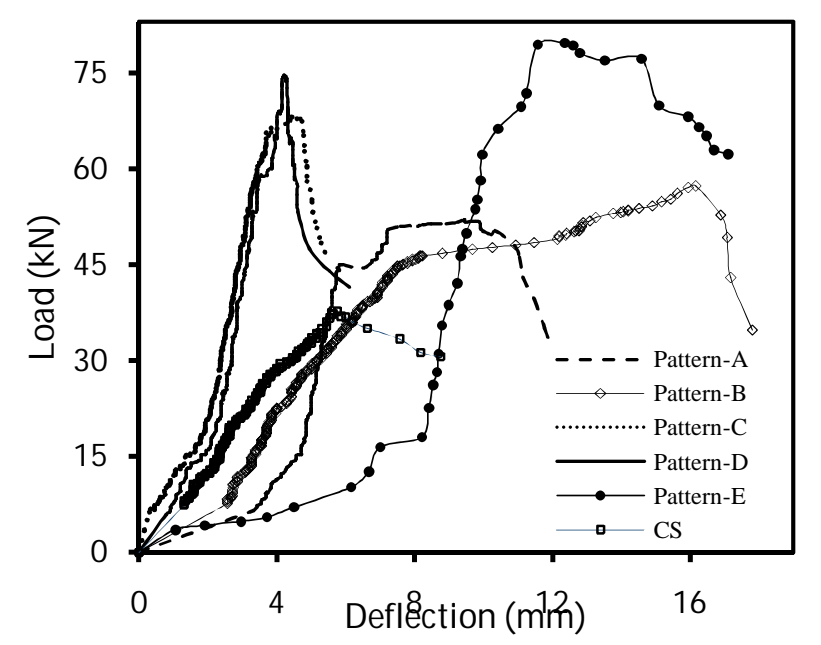

Figure 9: Load- deflection Curve of GFRP slabs with control slab (CS)

While considering the orientation of FRPs such as edge, corner, half, center and full, the slab strengthened with full wrapping is effective in increasing the flexural capacity. Amongst the different coverage area of FRPs, 25\%, 50\%, $100 \%$, the slab strengthened with $25 \%$ coverage area is effective in increasing the flexural capacity. Its coverage is $75 \%$ lesser than Pattern-E and $25 \%$ lesser than Pattern-C. When considering the $25 \%$ coverage area patterns, A, B, and $\mathrm{D}$, the slab strengthened with Pattern-D is effective in increasing the flexural capacity (Table 4). Whereas considering both coverage area and orientation also the Pattern-D (25\% coverage area and center wrapping) is effective in increasing the flexural capacity. From which it is found that the Pattern-D with CFRP as well as GFRP is superior to all the patterns in increasing the load carryingcapacity of the slab. Hence, FRP's orientation when closer to the center of the slab is effective in increasing the strength..

\section{CONCLUSION}

Based on the experimental result and comparison, the following conclusions can be drawn.

- Amongst the coverage area of FRP, 25\%, 50\%, $100 \%$, the slab strengthened with $25 \%$ coverage area is effective in increasing the flexural capacity.

- Considering the orientation of FRPs such as edge, corner, half, center and full, the slab strengthened with full wrapping is effective in increasing the flexural capacity.

- Considering both coverage area and orientation, the pattern-D (25\% coverage area and center wrapping) is effective in increasing the flexural capacity.

- In all the patterns, CFRP/GFRP sheets effectively minimizes the crack width.

- The average flexural strength of GFRP strengthened slabs are about $10 \%$ more than CFRP slabs.

- The delamination of FRPs, is only occurs at ultimate load level in RC slab.

\section{REFERENCES}

[1] Aljazaeri, Z. R., \& Myers, J. J. (2018). Flexure Performance of RC One-Way Slabs Strengthened with Composite Materials. Journal of Materials in Civil Engineering, 30(7), 1-10. https://doi.org/10.1061/(asce)mt.1943-5533.0002299

[2] Al-Bayati, G., Kalfat, R., Al-Mahaidi, R., \& Hashemi, J. (2018). Experimental study on crack propagation of CFRP-strengthened RC beams subjected to torsion. Australian Journal of Structural Engineering, 1-19. doi: $10.1080 / 13287982.2018 .1523293$

[3] Al-Saadi, N. T. K., Al-Mahaidi, R., \& Abdouka, K. (2016). Bond behaviour between NSM CFRP strips and concrete substrate using single-lap shear testing with cement-based adhesives. Australian Journal of Structural Engineering, 17(1), 28-38. doi: $10.1080 / 13287982.2015 .1116180$

[4] Al-Sulayvani, B. J., \& Al-Talabani, D. N. (2015). Strengthening and repair of circular RC slabs with openings using CFRP strips under repeated loading. Construction and Building Materials, 84, 73-83. https://doi.org/10.1016/j.conbuildmat.2015.03.058

[5] Balamurugan G., and Viwanathan T. S. (2020). Evaluation of the effects of orientation and coverage areas of FRP lamination bonded with two-way RC slabs - A modular approach. Civil Engineering and Architecture, 8(4). doi:10.13189/cea.2020.080432

[6] Bonacci, J. F and Maalej M. (2001). Behavioural Trends of RC Beams Strengthened with Externally Bonded FRP. Journal of Composites for Construction, 5(2) 102-113. https://doi.org/10.1061 /(ASCE)10900268(2001) 5:2(102)

[7] Delnavaz, A., \& Hamidnia, M. (2019). The assessment of shape configuration effect of CFRP strips on the lateral capacity of shear walls with different aspect 
Balamurugan G. et al., International Journal of Emerging Trends in Engineering Research, 8(9), September 2020, $5424-5429$

ratios. Australian Journal of Structural Engineering, 111. doi:10.1080/13287982.2019.1625103

[8] Gherdaoui, M., Guenfoud, M., \& Madi, R. (2018). Punching behavior of strengthened and repaired RC slabs with CFRP. Construction and Building Materials, 170 ,

$272-278$. https://doi.org/10.1016/j.conbuildmat.2018.03.093

[9] Hussein, M., \& Fawzy, T. M. (2010). Structural performance of CFRP-strengthened RC slabs in a corrosive environment. Journal of Composites for Construction, 14(6), 865-869. https://doi.org/10.1061/(ASCE)CC.1943-5614.0000133

[10] IS 269 (2015). Product manual for ordinary Portland cement [list of test equipment]. Bureau of Indian Standard, Manak Bhavan, 9 Bahadur Shah Zafar Marg, New Delhi

[11] IS 383 (1970). Specification for coarse and fine aggregates from natural sources for concrete [CED 2: Cement and Concrete]. Bureau of Indian Standard, Manak Bhavan, 9 Bahadur Shah Zafar Marg, New Delhi.

[12] IS 456 (2000). Plain and reinforced concrete code of practice. Bureau of Indian Standard, Manak Bhavan, 9 Bahadur Shah Zafar Marg, New Delhi.
[13] IS 808 (1989). Dimensions for Hot Rolled Steel Beam, Column, Channel and Angle Sections. Bureau of Indian Standard, Manak Bhavan, 9 Bahadur Shah Zafar Marg, New Delhi.

[14] IS 1786 (2000). High strength deformed steel bars and wires for concrete reinforcement-specification. Bureau of Indian Standard, Manak Bhavan, 9 Bahadur Shah Zafar Marg, New Delhi.

[15] Mazloom, M., Mehrvand, M., Pourhaji, P., \& Savaripour, A. (2019). Studying the effects of CFRP and GFRP sheets on the strengthening of selfcompacting RC girders. Structural Monitoring and Maintenance, 6(1), 47-66. https://doi.org/10.12989/smm.2019.6.1.047

[16] Mosallam, A. S., \& Mosalam, K. M. (2003). Strengthening of two-way concrete slabs with FRP composite laminates. Construction and Building Materials, 17(1), 43-54. https://doi.org/10.1016/S09500618(02)00092-2

[17] Saleh, H., Abdouka, K., Al-Mahaidi, R., \& Kalfat, R. (2018). Strengthening of slab-column connections against punching shear using FRP materials: state-ofthe-art review. Australian Journal of Structural Engineering, 1-19.

doi: $10.1080 / 13287982.2018 .1462901$ 